\title{
Innovation Barriers and the implementation of Open Innovation: Implications on The Performance of Small and Medium Enterprises in Indonesia
}

\author{
Jumi Apriza
}

\begin{abstract}
- this study aims to determine the effect of barriers felt by SMEs during the innovation process, such as barriers related to markets and institutions, financial barriers, employee behavior and organization barriers, as well as barriers on knowledge and cooperation on open innovation in breadth and depth, as well as knowing the effect of open innovation on innovation performance. SMEs in Indonesia that have never been studied before. The data used in this study is secondary data, namely data obtained from the results of the 2014 Indonesian Innovation Survey. The data analysis used in this study is Structural Equation Modeling (SEM) quantitative method with results showing that of the four groups of innovation barriers, only barriers related to employee behavior and organization, as well as knowledge and cooperation have a positive and significant relationship to open innovation in depth. Furthermore, there is a positive and significant relationship between open innovation and the innovation performance of SMEs.
\end{abstract}

Index Terms - Innovation Barriers, Open Innovation,

Emerging Economy, Innovation Performance, Small and Medium Enterprises, Indonesia.

\section{INTRODUCTION}

In today's competitive global era, innovation is one of the critical success factors for company growth and resilience. Many companies have implemented innovations with both closed innovation method and open innovation method. However, the majority of small and medium-sized companies still use a closed innovation approach, namely where the company only uses the company's internal resources in developing innovations. Henry Chesbrough stated that there is a paradigm shift from a closed innovation paradigm to an open innovation paradigm. In the open innovation model, companies can take advantage of both external and internal ideas to find and develop innovations (Chesbrough, 2003).

In Indonesia, currently many studies on innovation have been carried out, but the topic of research on open innovation is still lacking,especially studies linking the barriers of innovation and open innovation in the context of SMEs. Studies on open innovation and innovation barriers have been carried out in Indonesia, such as a study conducted by Hartono (2018). However, this research only covered innovation activities in large companies, while it has not been explored in the context of SMEs.Therefore, this study aims to complete the research gap on the theme of innovation barriers,

Jumi Apriza, Universitas Islam Indonesia open innovation, and their implications on innovation performance in SMEs in Indonesia which have never been studied before.

\section{LITERATURE REVIEW}

\section{A. Open Innovation}

Chesbrough (2003) stated that open innovation is the intentional use of inflows and outflows of knowledge to accelerate the company's internal innovation process and expand the market for the use of external innovations.

\section{B. Indicator of open innovation}

In this study, open innovation indicators will be used, namely External search breadth (ESB) and External search depth (ESD).Breadth measures the level of openness in terms of the number of external parties involved in the innovation process, whiledepth measures the extent to which specific external sources are used during the innovation process. This measurement refers to the importance of external parties(Bahemia \& Squire, 2010).

\section{Definition of SME}

In this study, we will follow the definition of SMEs put forward by the Central Bureau of Statistics (BPS/Badan Pusat Statistik), namely that SMEs are based on the number of its workers, where the number of workers in small businesses has amount from 5 to 19 people, while the number of workers in medium businesses has amount from 20 to 99 people.

\section{Innovation Barriers}

In achieving success on innovation, companies are faced with barriers or obstacles in innovating, thus it is very important to identify the obstacles faced during the innovation process because it can provide important knowledge for the company's decision-makers in overcoming these obstacles (D'Este etal., 2012).

Innovation barriers can be grouped into internal barriers such as financial barriers, employee behavior and organization, knowledge and cooperation, and external barriers such as market and institutional barriers (Hadjimanolis, 1999).

\section{- Market and Institutional Barriers}

Barriers related to markets and institutions are related to the external environment, namely, barriers that are outside the company which have several influences such as global 
competition, government policies, and economic uncertainty (Hadjimanolis, 1999).A case study conducted by $\mathrm{Fu}$ et al., (2014) stated that environmental innovation pressures encourage open innovation in China. Barriers related to markets and institutions show positive and significant results on openness to innovation. Other studies conducted by Katila $\&$ Shane (2005) and Frishammar \& Horte (2005) found a positive relationship between external economic uncertainty and the level of innovation. This is further reinforced by research by Galia \& Legros (2004)which found that lack of information on the external environment can be a barrier that is difficult for SMEs to avoid, but that way they will be able to implement the innovation process effectively.

In addition, this perception is in line with Miller's (1987) theory which explains that companies in a more volatile external environment have higher innovation potential because a volatile environment triggers companies to incorporate innovation into their business strategy to remain competitive and ultimately survive.

Therefore, this study proposes the following hypothesis:

$\mathrm{H}_{1 \mathrm{a}}$ : Barriers related to markets and institutions have a positive effecton SMEs in adopting the breadth of open innovation?

$\mathrm{H}_{1 \mathrm{~b}}$ : Barriers related to markets and institutions have a positive effecton SMEs in adopting the depth of open innovation.

\section{- Financial Barriers}

Financial barriersare barriersthat relate to the availability of internal and external finance as well as the cost of innovation (Pachouri \& Sharma,2016).Related to these barriers, previous studies show that financial barriers have a positive effect on companies adopting open innovation. For example, research conducted by Fu et al., (2014) showed financial barriers have a positive and significant effect on adopting open innovation in China. And in the context of SMEs, it is reinforced by a study conducted by Bigliardi \& Galati (2016) on the factors that hinder the implementation of open innovation in Italian SMEs, showing that financial barriers are identified as inhibiting factors in the implementation of open innovation. In addition, this is in line with transaction cost theory (Brouthers \& Nakos, 2004), which showed the adoption of open innovation is very relevant for SMEs because they face limited financial resources and have fewer technological assets, companies can take advantage of the open innovation paradigm to obtain resources and knowledge needed at a lesser cost and in lesser time.Thus, SMEs can achieve a better competitive position in the market (Dahlander \& Gann, 2010) Therefore, this study proposes the following hypothesis:

$\mathrm{H}_{2 \mathrm{a}}$ : Financial barriers have a positive effecton SMEs in adopting the breadth of open innovation?

$\mathrm{H}_{2 b}$ : Financial barriers have a positive effecton SMEs in adopting the depth of open innovation.

\section{- Employee Behavior and Organization Barriers}

Employee Behavior and Organization barriers are something that can hinder the progress or achievement of things related to human nature such as employee's resistance to innovation and organizational rigidity. Several studies have emphasized the role of employee's resistance to innovation based on problems such as poor communication, existing company norms, weak human resource practices, and lack of commitment from the management (Zwick, 2002).

Research conducted by Hartono \& Kusumawardhani (2018) showed that employee behavior and organization barriers have a positive and significant effect on all types of innovation.In addition, research conducted by Hartono (2018) showed only the employee behavior and organization barriers alone have a positive and significant effect on the company's openness to innovation.

Therefore, this study proposes the following hypothesis:

$\mathrm{H}_{3 \mathrm{a}}$ : Employee behavior and organization barriers have a positive effecton SMEs in adopting the breadth of open innovation?

$\mathrm{H}_{3 \mathrm{~b}}$ : Employee behavior and organization barriers have a positive effecton SMEs in adopting the depth of open innovation.

\section{- Knowledge and Cooperation Barriers}

Knowledge and Cooperation Barriers are something that can hinder the progress or achievement of something that includes the lack of qualified personnel, lack of information about technology and markets, and lack of collaborative activities. Another study conducted by Fu et al., (2014) showed that knowledge and organizational barriers have a positive and significant effect on the company's openness to innovation. Literature also shows that similar to larger organizations, open innovation in SMEs also relies on external sources (Lee et.al, 2010). Therefore, these barriers to the success of innovation can be overcome by utilizing an open innovation strategy. This is also in line with the attitude of SMEs to collaborate and establish strong relationships with external organizations in innovation activities to gain the knowledge needed (Bianchi et al., 2010).

Therefore, this study proposes the following hypothesis:

$\mathrm{H}_{4 \mathrm{a}}$ : Knowledge and cooperation barriers have a positive effecton SMEs in adopting the breadth of open innovation?

$\mathrm{H}_{4 \mathrm{~b}}$ : barriers have a positive effecton SMEs in adopting the depth of open innovation.

\section{- Open Innovation and SME Innovation Performance}

According to Price et al., (2013) innovation is an important factor in the formation of optimal performance. With good innovation performance, competitive advantage will be created. According to Ebersberger \& Herstad (2013), innovation performance is the result of selling new products or products that have been significantly updated. For example, research conducted by Hassan et al., (2018) showed open innovation has a positive and significant effect on SME's performance in Pakistan. This research also reveals that open innovation is an effective and growing tool for the success of SMEs. In addition, research conducted by Crema et al., (2014) on Italian SMEs also showed that open innovation has a positive impact on company performance. The research reveals that to obtain company performance, SMEs must use availableexternal resources and internal competencies. Furthermore, research conducted by Popa et 
al., (2017) also showed that open innovation practices contribute positively to the performance of SMEs in Spain. Therefore, this study proposes the following hypothesis:

$\mathrm{H}_{5}$ : Open innovation has a positive effect on the innovation performance of SMEs.

\section{METHODOLOGY}

This research is a quantitative descriptive study. The data used is secondary data, namely data obtained from the results of the 2014 Indonesian Innovation Survey, which is the latest data owned by Indonesia. The survey was conducted by the Research Center for the Development of Science and Technology (PAPPIPTEK) LIPI. A total of 833 samples were obtained in this study which included 564 small companies or $67.7 \%$ and 269 medium-sized companies or $32.3 \%$. The technique used in data collection to support this research is non-probability sampling. While the method used in sampling is purposive sampling.

\section{A. Market and Institutional Barriers}

In this study, the indicators used are (Hartono, 2018):

1. Uncertain demand for innovative goods/services

2. Lack of customers' acceptance

3. Lack of sufficient infrastructure to support innovation activities

4. Lack of industry standard

5. Lack of government regulation

\section{B. Financial Barriers}

In this study, the indicators used are (Hartono, 2018):

1. Lack of funds within your enterprise or group

2. Lack of finance from sources outside your enterprise

3. Innovation costs too high

4. Excessive perceived economic risks

\section{Employee Behavior and Organization Barriers}

In this study, the indicators used are (Hartono, 2018):

1. Staff resistance (being not open) towards change

2. Manager resistance (being not open) towards change

3. Organizational rigidities within the enterprise

\section{Knowledge and Cooperation Barriers}

In this study, the indicators used are (Hartono, 2018):

1. Lack of qualified personnel

2. Lack of information on technology

3. Lack of information on markets

4. Lack of ability to find cooperation partners for innovation

5. Inability to allocate labor in innovation activities because production has higher priority.

\section{E. Open Innovation}

In this study, the dependent variables of open innovation consist of $\mathrm{Y}_{1}$ : External Search breadth $\mathrm{Y}_{2}$ : External search depth. Following the measurement from research by Laursen \& Salter (2006), External search breadth refers to the number of search channels used by the company in its innovative activities while External search depth refers to the extent to which the company intensively attracts different search channels. In this study, the indicators used are (Hartono, 2018):

1. Suppliers of equipment, materials, components, or software.

2. Clients or customers.

3. Competitors/other enterprises in firm sector.

4. Consultants, commercial laboratories, or private R\&D institutes.

5. Universities/other higher education institutions.

6. The government/public research institutes.

7. Professional and industry associations.

8. Conferences, trade fairs, and exhibitions.

9. Scientific journals and trade/technical publications.

F. SME Innovation Performance

In this study, the SME innovation performance indicators used are incremental innovation (new to the company but not in the market) and radical innovation (new to the market) according to research by van Beers \& Zand, (2014).

In this study, the scale used on the open innovation variable consists of breadth and depth, where the measurement scale uses a binary scale, namely the breadth "YES (1) = if using external sources", "NO (0) = if not using external sources " and the depth "YES (1) = if the company uses external sources at a high level", NO $(0)=$ if the use of a given external source is rarely used, moderately used, or not used at all. On the barrier's variables such as market and institutional barriers, financial barriers, employee behavior and organization barriers as well as knowledge and cooperation barriers, an ordinal scale is used, namely "1 = Not relevant", "2 = Low", "3 = Medium", 4 = High".And for the innovation performance variable, the measurement scale is " $(\%)$ Proportion of sales of new product innovations that have never existed before in the Indonesian market (radical innovation)", "(\%) proportion of sales of new product innovations that have never been produced by the company (incremental innovation)".

\section{RESULT AND DISCUSSION}

A.Descriptive Analysis

1. Innovation Barriers Variable

The results of the analysis on the innovation barriers variable can be shown in the following table; 
Innovation Barriers and the implementation of Open Innovation: Implications on The Performance of Small and Medium Enterprises in Indonesia

Table 1 Assessment of the Variable Barriers to Innovation

\begin{tabular}{|c|c|c|c|c|c|}
\hline & $\mathrm{N}$ & Minimum & Maximum & Mean & $\begin{array}{l}\text { Std. } \\
\text { Deviation }\end{array}$ \\
\hline \multicolumn{6}{|c|}{ Market and Institutional Barriers } \\
\hline Uncertain Demand & 833 & 0 & 4 & 2.1369 & 1.178941 \\
\hline Customers' Acceptance & 833 & 0 & 4 & 2.0192 & 1.134941 \\
\hline Infrastructure & 833 & 0 & 4 & 2.1261 & 1.218726 \\
\hline Industry Standard & 833 & 0 & 4 & 2.0732 & 1.216144 \\
\hline Government Regulation & 833 & 0 & 4 & 1.9340 & 1.047759 \\
\hline Average & & & & 2.0579 & \\
\hline \multicolumn{6}{|l|}{ Financial Barries } \\
\hline Internal Fund & 833 & 0 & 4 & 2.3097 & 1.27574 \\
\hline External Fund & 833 & 0 & 4 & 2.0936 & 1.256089 \\
\hline High Costs & 833 & 0 & 4 & 2.3950 & 1.276196 \\
\hline Economic Risk & 833 & 0 & 4 & 2.3469 & 1.257064 \\
\hline Average & & & & 2.2863 & \\
\hline \multicolumn{6}{|c|}{ Employee Behavior and Organization Barriers } \\
\hline Staff Resistance & 833 & 0 & 4 & 1.9688 & 1.191511 \\
\hline Manager resistance & 833 & 0 & 4 & 1.8211 & 1.154188 \\
\hline Organizational rigidities & 833 & 0 & 4 & 1.8764 & 1.165543 \\
\hline Average & & & & 1.8888 & \\
\hline \multicolumn{6}{|c|}{ Knowledge and Cooperation Barriers } \\
\hline Personnel Quality & 833 & 0 & 4 & 2.1309 & 1.224125 \\
\hline Information Technology & 833 & 0 & 4 & 2.0816 & 1.192146 \\
\hline Market Information & 833 & 0 & 4 & 2.0540 & 1.167761 \\
\hline Cooperation & 833 & 0 & 4 & 2.1369 & 1.211126 \\
\hline Labour & 833 & 0 & 4 & 1.9316 & 1.11755 \\
\hline Average & & & & 2.0670 & \\
\hline Total Avarage & & & & 2.0750 & \\
\hline
\end{tabular}

Source: Secondary Data processed 2021

Based on the results of the descriptive analysis as shown in Table 1, it shows that the average respondent's assessment of innovation barriers is 2.0750. This shows that the innovation barriers perceived by SMEs are quite important in adopting their innovations. On average, scores for barriers related to financing and risk, including Internal Funds, External Funds, High Costs, and High Risks, scored above 2 and these financial barriers had the highest average of 2.2863, which is included in the between the top three average scores compared to other types of barriers. Meanwhile, barriers on behavior and organization are the least important types of barriers according to SMEs in implementing their innovations.

This finding confirms previous studies which revealed that financial barriers are more important than other barriers. For example, financial-related barriers are more influential than other internal and other external barriers in the case of innovation adoption not starting, being delayed, or delayed among firms in European countries (Canepa \& Stoneman, 2007). The top barriers related to financial factors in this study are also similar to previous studies in the context of developing countries. Hartono's research (2018) showed that financial barriers are the most important barriers felt by manufacturing industry actors in Indonesia.

\section{Open Innovation Variable}

The results of the descriptive analysis on the open innovation variable can be shown in the following table:

Table 2 Assessment of Open Innovation Variables

\begin{tabular}{|l|l|l|l|l|l|}
\hline & $\mathrm{N}$ & Minimum & Maximum & Mean & Std. Deviation \\
\hline Breadh & 833 & .000 & 9.000 & 5.42377 & 4.406809 \\
Depth & 833 & .000 & 8.000 & .89316 & 1.346957 \\
Valid N (listwise) & 833 & & & & \\
\hline
\end{tabular}

Source: Secondary Data processed 2021

Based on the results of the descriptive analysis shown in Table 2, it shows that the average respondent's assessment to open innovation is 5.4237 for breadth and 0.89316 for depth. These results indicate that the average breadth of open innovation is higher than the depth, which is 5.42377 and 0.89316 , respectively. This means that each SME uses on average 5 to 6 different external knowledge sources for innovation and uses 1 external knowledge source intensively. 
The results of the analysis on the innovation performance variable can be shown in the following table:

Table 3 Assessment of Performance Innovation Variables

\begin{tabular}{|l|l|l|l|l|l|}
\hline & $\mathrm{N}$ & Minimum & Maximum & Mean & Std. Deviation \\
\hline Radical Innovation & 833 & .000 & 200.000 & 12.27371 & 23.972931 \\
\hline Incremental Innovation & 833 & .000 & 100.000 & 20.85474 & 31.072137 \\
\hline Innovation Performance & 833 & .000 & 200.000 & 33.12845 & 41.174395 \\
\hline
\end{tabular}

Source: Secondary Data processed 2021

Based on the results of the descriptive analysis as shown in Table 3, it shows that the average respondent's assessment of innovation performance is 33.128. When compared, incremental innovation performance, incremental has a higher performance of $20.85 \%$ than radical innovation which is only $12.273 \%$. This shows that SMEs prefer to innovate by improving andreusingexisting productsand processes to improve their products, rather than having to make major changes. Carrying out radical innovations with major changes, of course, requires greater costs, all the while financial barriers are a major problem for SMEs in Indonesia.

\section{A.Hypothesis Testing}

Hypothesis testing with SEM analysis obtained the following results:

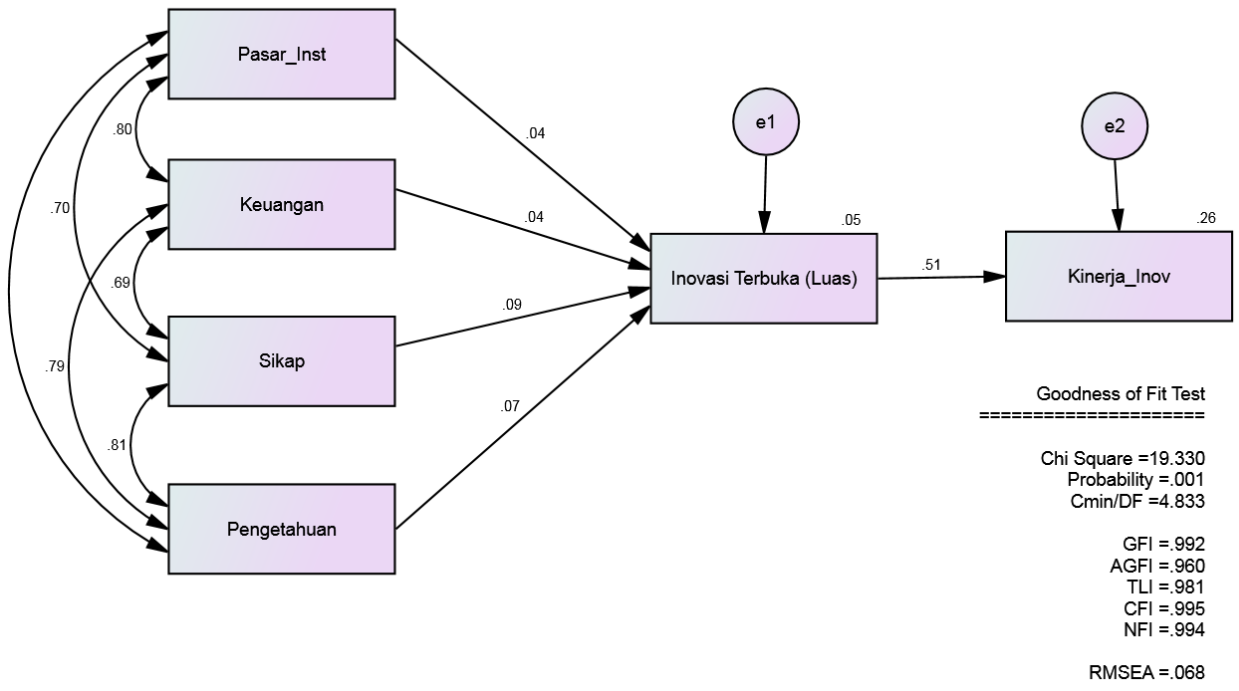

Figure 1 Test Result of the Open Innovation model (Breadth)

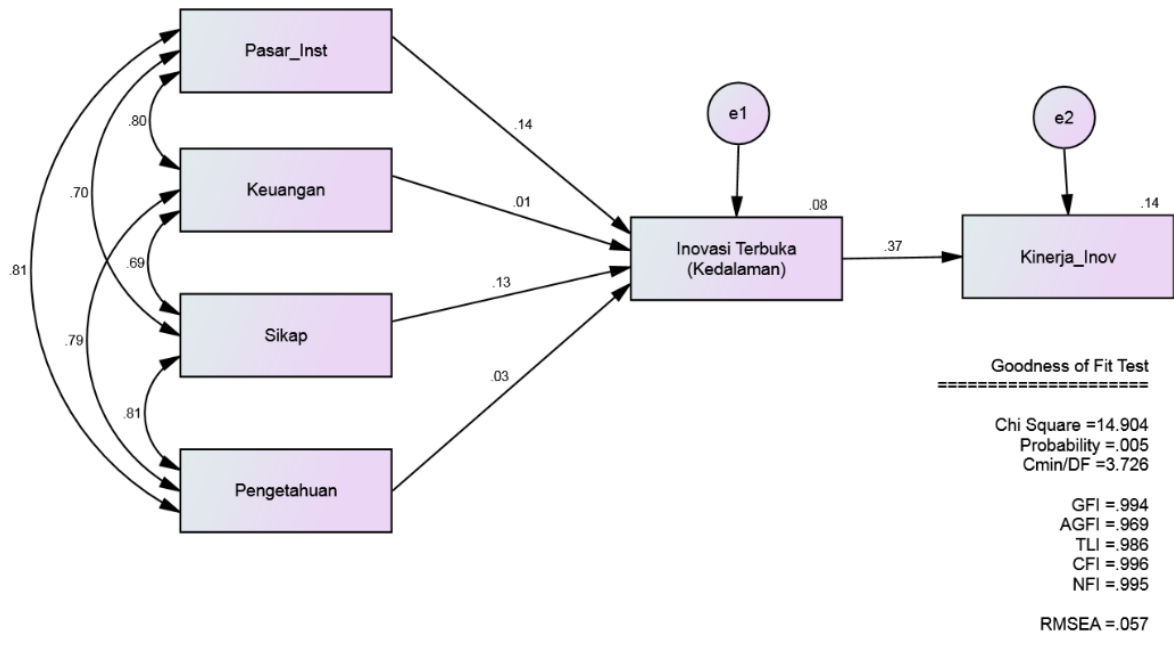

Figure 1 Test Result of the Open Innovation model (Depth)

Based on the description of the figure above, one can explain the testing results from the first hypothesis to

the fifth hypothesis. While the estimated results of the SEM analysis can be shown in the following table: 
Innovation Barriers and the implementation of Open Innovation: Implications on The Performance of Small and Medium Enterprises in Indonesia

Table 4 Estimation of SEM Analysis Results

\begin{tabular}{|c|c|c|c|}
\hline Relationship between Variabel & Breadth & Depth & $\begin{array}{c}\text { Innovation } \\
\text { Performance }\end{array}$ \\
\hline Market and Institutional $\rightarrow$ Open Innovatiom & $0.039(0.547)$ & $0.139(* *)$ & \\
\hline Financial $\rightarrow$ Open Innovation & $0.043(0.492)$ & $0.008(0.898)$ & \\
\hline $\begin{array}{c}\text { Employee Behavior and Organization } \rightarrow \text { Open } \\
\text { Innovation }\end{array}$ & $0.090(0.119)$ & $0.132(* *)$ & \\
\hline Knowledge and Cooperation $\rightarrow$ Open Innovation & $0.070(0.340)$ & $0.033(0.651)$ & $0.509(* * *)$ \\
\hline Breadth $\rightarrow$ Innovation Performance & & & $0.372(* * *)$ \\
\hline Depth $\rightarrow$ Innovation Performance & & & \\
\hline
\end{tabular}

Source: Secondary Data processed 2021

\section{Hypothesis Testing: First Alternative Breadth}

The test results on the market and institutional barriers to the breadth of open innovation yielded a coefficient path (Standardized) of 0.039 and a probability (p-value) of $0.547>0.05$

These results indicate that there is no significant effect of barriers related to markets and institutions to the breadth of openinnovation. This means that the first hypothesis which states " $\mathrm{H}_{1 \mathrm{a}}$ : Financial barriers have a positive effecton SMEs in adopting the breadth of open innovation", is rejected.

\section{Depth}

The test result on the market and institutional barriers variable to the depth of open innovation yielded a coefficient path (Standardized) of 0.139 and a probability ( $p$-value) of $0.029<0.05$. The result indicates that there is a significant effect of barriers related to markets and institutions on the depth of open innovation. This means that the first hypothesis which states " $\mathrm{H}_{1 \mathrm{~b}}$ : Financial barriers have a positive effecton SMEs in adopting the breadth of open innovation", is supported.The positive coefficient (0.139) indicates that the better the barriers related to market and institutions to depth are, the more open innovation adoption will be, and conversely, lower market and institutional barriers towards depth will reduce open innovation. This study supports the research conducted by $\mathrm{Fu}$ et al., (2014) which stated that environmental innovation pressures encourage open innovation in China.

\section{Hypothesis Testing: Second Alternative}

\section{Breadth}

The test result on the financial barriers variable to the breadth of open innovation yielded a coefficient path (Standardized) of 0.043 and a probability (sig) of $0.492>0.05$. The result indicates that there is no significant effect of barriers related to financial barriers on the breadth of open innovation. This means that the second hypothesis which states " $\mathrm{H}_{2 \mathrm{a}}$ : Financial barriers have a positive effecton SMEs in adopting the breadth of open innovation", is rejected.

\section{Depth}

The test results on the financial barriers variable to the depth of open innovation yieldeda coefficient path (Standardized) of 0.008 and a probability ( $\mathrm{sig}$ ) of $0.898>0.05$. The result indicates that there is no significant effect of barriers related to financial barriers on the depth of open innovation. This means that the second hypothesis which states " $\mathrm{H}_{2 \mathrm{~b}}$ : Financial barriers have a positive effecton SMEs in adopting the depth of open innovation", is rejected.
The results of the study support Hartono's research (2018) which found financial barriers have no significant effect on open innovation both in terms of breadth and depth.

\section{Hypothesis Testing: Third Alternative}

\section{Breadth}

The test result on the employee behavior and organization barriers variable to the breadth of open innovation yielded a coefficient path (Standardized) of 0.090 and a probability (sig-t) of $0.119>0.05$. The result indicates that there is no significant effect of employee behavior and organization barriers on the breadth of open innovation. This means that the third hypothesis which states $" \mathrm{H}_{3 \mathrm{a}}$ : Employee behavior and organization barriers have a positive effecton SMEs in adopting the breadth of open innovation", is rejected.

Depth

The test result on the employee behavior and organization barriers variable to the depth of open innovation yielded a coefficient path (Standardized) of 0.132 and a probability (sig-t) of $0.020<0.05$. The result indicates that there is a significant effect of employee behavior and organization barriers on the depth of open innovation. The positive coefficient result $(0.132)$ indicates that the higher the employee behavior and organization barriers towards depth is, the higher the SME's in adopting open innovation will be. This means that the third hypothesis which states " $\mathrm{H}_{3 \mathrm{~b}}$ : Employee behavior and organization barriers have a positive effecton SMEs in adopting the breadth of open innovation", is supported.

The study is in line with research conducted by Hartono \& Kusumawardhani (2018) which showed that employee behavior and organization barriers have a positive and significant effect on all types of innovation. In this case, barriers provide opportunities and learning experiences when companies carry out innovation activities, but these barriers do not prevent companies from innovating because they can overcome these barriers.

\section{Hypothesis Testing: Fourth Alternative Breadth}

The test result on the knowledge and cooperation barriers variable to the breadth of open innovation yielded a coefficient path (Standardized) of 0.070 and a probability (sig-t) of $0.340>0.05$. The result indicates that there is no significant effect of knowledge and cooperation barriers on the breadth of open innovation. This means that the fourth hypothesis which states $" \mathrm{H}_{4 \mathrm{a}}$ : Knowledge and cooperation barriers have a positive effecton SMEs in adopting the breadth of open innovation", is rejected. 


\section{Depth}

The test result on the knowledge and cooperation barriers variable to the depth of open innovation yielded a coefficient path (Standardized) of 0.033 and a probability (sig-t) of $0.651>0.05$. The result indicates that there is no significant effect of knowledge and cooperation barriers on the depth of open innovation. This means that the fourth hypothesis which states " ${ }_{4 \mathrm{~b}}$ : Knowledge and cooperation barriers have a positive effecton SMEs in adopting the depth of open innovation", is rejected.

The results of this study are in line with research conducted by Hartono and Kusumawardhani (2018) which foundknowledge and cooperation barriers have a negative effect on open innovation.

\section{Hypothesis Testing: Fifth Alternative}

The test result on the breadth variable of open innovation towards innovation performance obtained a path coefficient (Standardized) of 0.509 and a probability (sig-t) of 0.000 $<0.05$, which means that there is a significant effect. The test result of the depth towards innovation performance yielded a path coefficient (Standardized) of 0.372 and a probability (sig-t) of $0.000<0.05$, which means that there is a significant effect of innovation depth on innovation performance. The results show that there is a significant effect of open innovation on innovation performance. The positive coefficient results indicate that the higher the open innovation is, the higher the innovation performance in SMEs will be. This means that the fifth hypothesis which states " $\mathrm{H}_{5}$ : Open innovation has a positive effect on the innovation performance of SMEs" is supported.

This study reinforces the research conducted by Hassanet al., (2018) that showed open innovation has a positive and significant effect on SME's performance in Pakistan. This study also reveals that open innovation is an effective growing tool for the success of SMEs.

\section{CONCLUSION}

Based on the above explanation, SMEs that experience barriers related to markets and institutions have no effect on adopting open innovation, but on the contrary, there is an influence on depth in adopting open innovation. Furthermore, SMEs that experience financial-related barriers do not affect adopting open innovation both in breadth and in-depth. This means that financial barriers have not been able to encourage SMEs to carry out open innovation. Furthermore, SMEs that experience barriers related to employee behavior and organization have no effect on adopting open innovation, but on the contrary, there is an influence on depth in adopting open innovation. In addition, SMEs that experience Knowledge and Cooperation barriers have no effect on adopting open innovation both in breadth and depth. This means that the importance of the knowledge and cooperation barriers experienced by SMEs have not been able to encourage open innovation. Open innovation has a positive effect on the innovation performance of SMEs. Open innovation, both in breadth and depth, has a significant effect on innovation performance in SMEs in Indonesia. This means that the better SMEs in adopting open innovation is, the higher the innovation performance will be, and conversely, SMEs that do not adopt open innovation will have low innovation performance.

\section{Limitation and Future Research}

The researchers were only using secondary data, so they do not directly conduct the research, so there are still many innovation barriers that have not been well revealed. The research was carried out in an outdated period, so the impact of the COVID-19 pandemic, which is felt thoroughly by SMEs, could be a separate barrier in adopting open innovations. The large number of samples with different types of industry certainly also affects the level of innovation adoption of each industry and the barriers experienced, so it is necessary to differentiate research in different industrial sectors such as the service and manufacturing industries. Based on these limitations, a suggestion is made for future researchers, that is to conduct comparable research by distributing questionnaires directly to certain areas, both offline (face to face) and online (Google form), by developing existing innovation barriers. Further research can include the Covid-19 pandemic as one of the external barriers to the adoption of openinnovation and develop comparative research on SMEs in the manufacturing and service industries.

\section{REFERENCES}

[1] Bahemia, H., \& Squire, B. (2010). "A contingent perspective of open innovation in new product development projects". International Journal of Innovation Management, 14(04), 603-627.

[2] Bianchi, M., Campodall'Orto, S., Frattini, F., \& Vercesi, P. (2010). "Enabling open innovation in small-and medium-sized enterprises: how to find alternative applications for your technologies". R\&d Management, 40(4), 414-431.

[3] Bigliardi, B., \& Galati, F. (2016). "Which factors hinder the adoption of open innovation in SMEs?". Technology Analysis \& Strategic Management, 28(8), 869-885.

[4] Brouthers, K. D., and G. Nakos. 2004. "SME Entry Mode Choice and Performance: A Transaction Cost Perspective." Entrepreneurship Theory and Practice 28 (3): 229-247.

[5] Chesbrough, H., (2003). "Open Innovation: The new imperative for creating and profiting fromtechnology". Harvard Business School Press, Boston, MA.

[6] Crema, M., Verbano, C., \& Venturini, K. (2014). "Linking strategy with open innovation and performance in SMEs". Measuring Business Excellence.

[7] Dahlander, L., and D. M. Gann. 2010. "How Open is Innovation?" Research Policy 39 (6): 699-709. Dodgson, M., D. Gann, and A. Salter. 2006. "The Role of Technology in the Shift Towards Open Innovation: The Case ofProcter \& Gamble." R\&D Management 36 (3): 333-346.

[8] D’Este, P., Iammarino, S., Sanova, M., \& Tunzelmann, N. V. (2012). "What hampers innovation? Revealed barriers versus deterring barriers". Research Policy, 41(2), 482-488.

[9] Ebersberger, B., \& Herstad, S. (2013). "The relationship between international innovation collaboration, intramural R\&D and SMEs' innovation performance: A quantile regression approach". Applied Economics Letters, 20, 626-630.

[10] Fu, X., Li, J., Xiong, H., \& Chesbrough, H. (2014). "Open innovation as a response to constraints and risks: evidence from China". Asian Economic Papers, 13(3), 30-58.

[11] Hadjimanolis, A. (1999). "Barriers to innovation for SMEs in a small less developed country (Cyprus)". Technovation, 19(9), 561-570.

[12] Hartono, A. (2018). "DO INNOVATION BARRIERS DRIVE A FIRM TO ADOPT OPEN INNOVATION? INDONESIAN FIRMS'EXPERIENCES”. Academy of Strategic Management Journal, 17(6), 1-12. 
[13] Hartono, A., \& Kusumawardhani, R. (2018). "Searching widely or deeply? The impact of open innovation on innovation and innovation performance among indonesian manufacturing firms". Journal of Indonesian Economy and Business, 33(2), 123-142.

[14] Hassan, M. U., Iqbal, Z., Malik, M., \& Ahmad, M. I. (2018). "Exploring the role of technological developments and open innovation in the survival of SMEs: an empirical study of Pakistan". International Journal of Business Forecasting and Marketing Intelligence, 4(1), 64-85.

[15] Katila, R., and S. Shane (2005). "When Does Lack of Resources Make New Firms Innovative?" Academy of ManagementJournal 48, 814-829.

[16] [16] Laursen, K., \& Salter, A. (2006). "Open for innovation: the role of openness in explaining innovation performance among UK manufacturing firms". Strategic management journal, 27(2), 131-150.

[17] Lee, S., Park, G., Yoon, B., \& Park, J. (2010). "Open innovation in SMEs-An intermediated network model”. Research policy, 39(2), 290-300.

[18] Legros, F., and D. Galia (2004). "Complementarities between Obstacles to Innovation: Evidence from France,"Research Policy 33, $1185-1199$.

[19] Miller, D. (1987). "The Structural and Environmental Correlates of Business Strategy," Strategic ManagementJournal 8, 55-76.

[20] Popa, S., Soto-Acosta, P., \& Martinez-Conesa, I. (2017). “Antecedents, moderators, and outcomes of innovation climate and open innovation: An empirical study in SMEs". Technological Forecasting and Social Change, 118, 134-142.

[21] Price, D. P., Stoica, M., \& Boncella, R. J. (2013). "The relationship between innovation, knowledge, and performance in family and non-family firms: an analysis of SMEs". Journal of innovation and Entrepreneurship, 2(1), 1-20.

[22] van Beers, C., \& Zand, F. (2014). "R\&D Cooperation, Partner Diversity, and Innovation Performance: An Empirical Analysis". Journal of Product Innovation Management, 31(2), 292-312.

[23] Zwick, T. (2002). "Employee Resistance against Innovations," International Journal of Management 23, 542- 552. 